\title{
Available Transfer Capability Enhancement with FACTS Devices in the Deregulated Electricity Market
}

\author{
B.V. Manikandan ${ }^{\dagger}$, S. Charles Raja* and P. Venkatesh*
}

\begin{abstract}
In order to facilitate the electricity market operation and trade in the restructured environment, ample transmission capability should be provided to satisfy the demand of increasing power transactions. The conflict of this requirement and the restrictions on the transmission expansion in the restructured electricity market has motivated the development of methodologies to enhance the available transfer capability (ATC) of existing transmission grids. The insertion of flexible AC transmission System (FACTS) devices in electrical systems seems to be a promising strategy to enhance single area ATC and multi-area ATC. In this paper, the viability and technical merits of boosting single area ATC and multi-area ATC using Thyristor controlled series compensator (TCSC), static VAR compensator (SVC) and unified power flow controller (UPFC) in single device and multi-type three similar and different device combinations are analyzed. Particle swarm optimization (PSO) algorithm is employed to obtain the optimal settings of FACTS devices. The installation cost is also calculated. The study has been carried out on IEEE 30 bus and IEEE 118 bus systems for the selected bilateral, multilateral and area wise transactions.
\end{abstract}

Keywords: Available transfer capability, Flexible AC transmission systems, Particle swarm optimization, Power transfer dsistribution factors, Participation factors, Installation cost

\section{Introduction}

The restructuring of the electric industry throughout the world aims to create competitive markets to trade electricity and generates a host of new technical challenges to market participants and power system researchers. For transmission networks, one of the major consequences of the non-discriminatory open-access requirement is a substantial increase of power transfers, which demand adequate available transfer capability (ATC) to ensure all transactions are economical. Researchers have proposed the computation of ATC using AC power transfer distribution factors (ACPTDF) [1]-[3]. New methods of evaluating ATC in a competitive environment are proposed in previous research[4], [5]. With the introduction of competition in the utility industry, it is possible for customers to buy less expensive electrical energy from remote location. As a result, system operators face the need to monitor and coordinate power transactions taking place over long distances in different areas. Therefore, it becomes essential to evaluate multi-area ATC, and a novel method for determining multi-area ATC has been presented in the literature[6].

Sufficient ATC should be guaranteed to support free market trading and maintain an economical and secure operation over a wide range of system conditions. However, tight restrictions on the construction of new facilities due to

\footnotetext{
$\dagger$ Corresponding Author: Mepco Schlenk Engineering College, Sivakasi Tamilnadu, India. (bvmani73@yahoo.com)

* Thiagarajar College of Engineering, Madurai, TamilNadu, India. (charlesrajas@tce.edu,pveee@tce.edu)

Received: March 25, 2010; Accepted: June 7, 2010
}

the increasingly difficult economic, environmental, and social problems, have led to a much more intensive shared usage of existing transmission facilities by utilities and independent power producers (IPPs). These concerns have motivated the development of strategies and methodologies to boost the ATC of existing transmission networks.

FACTS technology enables line loading to increase flexibly, in some cases, even up to the thermal limits. Therefore, it can theoretically offer an effective and promising alternative to conventional methods for ATC enhancement. Undoubtedly, it is very important and imperative to carry out studies on exploitation of FACTS technology to enhance ATC [7]-[10]. The modeling of FACTS devices for power flow studies, the role of such modeling for power flow control and the integration of these devices into power flow studies were reported in the literature [11], [12]. Modeling and the role of important FACTS devices like static VAR compensator (SVC), Thyristor controlled series compensator(TCSC) and unified power flow controller (UPFC) in solving power system restructuring issues have been previously reported [13]-[15].

Some well established search algorithms such as GA [16] and evolutionary programming (EP) [17], [18] were successfully implemented to solve simple and complex problems efficiently and effectively. Most of the population based search approaches are motivated by evolution as seen in nature. Particle Swarm Optimization (PSO), on the other hand, is motivated from the simulation of social behavior and was introduced by Eberhart and Kennedy [19]. Instead of using evolutionary operators to manipulate individuals, like in other evolutionary computational algo- 
rithms, each individual in PSO flies in the search space with velocity that is dynamically adjusted according to its own and its companion's flying experience. The velocity of the particle that is updated according to its own previous best position and the previous best position of its companions and more information are available in previous research [20]. PSO is now applied for solving electrical engineering related problems [21].

In this paper, single area ATC is calculated using ACPTDF and multi-area ATC with ACPTDF and participation factors $(\mathrm{PFs})$ in combined economic emission dispatch (CEED) environment [6], [18]. An attempt is made to enhance ATC using TCSC, SVC and UPFC in single device and multi-type three similar and different device combinations. Limiting element strategy is proposed for placement of FACTS devices. Both bilateral and multilateral transactions are considered for single area ATC and area- wise transaction is considered for multi-area ATC enhancement. The optimal settings of FACTS devices are obtained from PSO Algorithm. The installation cost of FACTS devices [22] has also been calculated. For the selected transactions, the best single device type and multi-type device combination have been suggested with reference to ATC enhanced value and installation cost. The results are illustrated on both IEEE 30 bus and IEEE 118 bus systems.

\section{ATC}

ATC is a measure of the transfer capability remaining in the physical transmission network for further commercial activity over and above the already committed uses. It can be expressed as follows:

$$
\text { ATC }=\text { TTC }- \text { Existing Transmission Commitments }
$$

Where, Total Transfer Capability (TTC) is defined as the amount of electric power that can be transferred over the interconnected transmission network or particular path or interface in a reliable manner while meeting all of a specific set of defined pre and post contingency conditions.

ATC at the base case, between bus $m$ and bus $n$ using line flow limit (thermal limit) criterion is mathematically formulated using ACPTDF as given in the below equation:

$$
A T C_{m n}=\min \left\{T_{i j, m n}\right\}, i j \in N_{L}
$$

Where $T_{i j, m n}$ denotes the transfer limit values for each line in the system. It is given by the following:

$$
T_{i j, m n}=\left\{\begin{array}{lc}
\frac{\left(P_{i j}^{\max }-P_{i j}^{0}\right)}{A C P T D F_{i j, m n}} ; & A C P T D F_{i j, m n}>0 \\
\alpha \text { (infinite) } ; & A C P T D F_{i j, m n}=0 \\
\frac{\left(-P_{i j}^{\max }-P_{i j}^{0}\right)}{A C P T D F_{i j, m n}} ; & A C P T D F_{i j, m n}<0
\end{array}\right\}
$$

Where the following holds true:

$P_{i j}{ }^{\max }$ is the MW power limit of a line between bus $i$ and $j$.

$P_{i j}{ }^{o}$ is the base case power flow in line between bus $i$ and $j$.

$N_{L}$ is the total number of lines.

$A C P T D F_{i j, m n}$ is the power transfer distribution factor for the line between bus $i$ and $j$ when a transaction is taking place between bus $m$ and $n$.

ACPTDF as given in equation (3) is operating point dependent and was computed using Jacobian inverse. ACPTDFs remain fairly constant for reasonable variations in power injections. The method of formulating ACPTDF is common for both single area and multi-area ATC evaluation and this is explained in section 2.2. For multi-area ATC calculation, in addition to ACPTDFs, PFs should also be included and it is explained in section 2.3. In this paper, the optimal settings of generators under CEED environment are considered as a base case power flow, which is explained in section 2.1 .

\subsection{CEED Problem Formulation}

In the restructured environment, generator companies are generally responsible for the re-dispatch of power by considering the emissions according to state laws and submit their bids to the transmission system operator, which is responsible for calculating ATC before committing the transactions. However, in most developing countries, the restructuring process of power industry is still in the infant stage wherein the structure is vertically integrated but the power is purchased from IPPs to meet the growing demand. Hence, the regional transmission operator is responsible for the re-dispatch of generator power by considering the physical limits of the system and the emissions standards. Furthermore, there are some power markets that support both bilateral transactions based on ATC and centralized dispatch based on bids. In these markets, assured firm transactions are implemented first and then they will follow centralized dispatch mechanism with the remaining transfer capacity. Therefore the proposed CEED based ATC calculation method can be well suited for such cases described above.

The optimization of CEED problem has been mathematically formulated and is given by the following equation:

$$
\phi=\min \sum_{i=1}^{N g} f_{i}(F C, E C)
$$


Where $\phi$ is the optimal cost of generation (US\$/h) and $N_{g}$ represents the number of generators connected in the network. $F C$ represents the total fuel cost of generation in $\mathrm{US} \$ \mathrm{~h}$ and $E C$ denotes the total emission of generation in $\mathrm{lb} / \mathrm{h}$. The cost is optimized with the constraints such as power flow equation of the power network, satisfying power balance equation, inequality constraint on real power generation of each generator $i$, inequality constraint on voltage of each PQ bus and power flow limit on each transmission line.

The bi-objective optimization problem (4) is converted into single optimization problem by introducing price penalty factor, $h$ in $\$ / \mathrm{lb}$, which blends fuel cost with emission, as expressed by the following:

$$
\text { Minimize } \phi=(F C+h E C)
$$

CEED optimization problem is solved using EP, subject to the constraints mentioned above. More information is also available in the literature [6], [18].

\subsection{ACPTDF Formulation}

ACPTDFs determine the linear impact of a transfer (or changes in power injection) on the elements of the power system. These values provide a linearized approximation of how the flow on the transmission lines and interfaces change in response to transaction between the seller and the buyer. Considering a bilateral transaction $t_{k}$ between a seller bus $m$ and buyer bus $n$, line $l$ carries the part of the transacted power and is connected between buses $i$ and $j$. For a change in real power in the transaction between the above buyer and seller by $\Delta t_{k} \mathrm{MW}$, if the change in a transmission line quantity $q_{1}$ is $\Delta q_{1}$, power transfer distribution factors can be defined as follows:

$$
A C P T D F_{i j, m n}=\frac{\Delta q_{l}}{\Delta t_{k}}
$$

The transmission quantity $q_{l}$ can be either real power flow from bus $i$ to bus $j\left(P_{i j}\right)$ (or) real power flow from bus $j$ to bus $i\left(P_{j i}\right)$. The above factors have been proposed to compute at a base case load flow with results using the sensitivity properties of NRLF Jacobian. Consider full Jacobian in polar coordinates $\left[\mathrm{J}_{\mathrm{T}}\right]$, which is defined to include all the buses except slack (also including $\Delta \mathrm{Q}-\Delta \mathrm{V}$ equations for PV buses), we get the following:

$$
\left[\begin{array}{l}
\Delta \delta \\
\Delta V
\end{array}\right]=\left[\begin{array}{ll}
\frac{\partial P}{\partial \delta} & \frac{\partial P}{\partial V} \\
\frac{\partial Q}{\partial \delta} & \frac{\partial Q}{\partial V}
\end{array}\right]^{-1}\left[\begin{array}{l}
\Delta P \\
\Delta Q
\end{array}\right]=\left[J_{T}\right]^{-1}\left[\begin{array}{l}
\Delta P \\
\Delta Q
\end{array}\right]
$$

In a base case load flow, if only one of the $k^{\text {th }}$ bilateral transactions is changed by $\Delta \mathrm{t}_{\mathrm{k}} \mathrm{MW}$, only the following two entries in the mismatch vector on right hand side of (7) will be non zero.

$$
\Delta P_{i}=\Delta t_{k} \quad \Delta P_{j}=-\Delta t_{k}
$$

With the above mismatch vector elements, the change in voltage angle and magnitude at all buses can be computed from (7) \& (8) and, hence, the new voltage profile can be calculated. These can be utilized to compute all the transmission quantities $q_{l}$ and hence the corresponding in these quantities $\Delta q_{l}$ from the base case. Once the $\Delta q_{l}$ for all the lines corresponding to a change in transaction $\Delta t_{k}$ is known, PTDFs can be obtained from (6). These ACPTDFs, which are computed at a base load flow condition, have been utilized for computing change in transmission quantities at other operating conditions as well.

\subsection{PF for Multi-area ATC Calculation}

For transaction taking place between two areas i.e. one is the seller area and the other is the buyer area, the multiarea

ATC problem formulation is as follows:

For each generator inside the area, the actual participation factor used is the following;

$$
P F_{i}=\frac{\text { Gen }_{i}}{\sum\left(\text { All Gen }_{i} \text { in an area }\right)}
$$

Where $\mathrm{Gen}_{i}$ represents the real power generation capacity of generator $i$. Assuming the inverse of Jacobian i.e., $\left[J_{T}\right]^{-1}$ is $\left[S_{T}\right]$, equation (7) can be written as follows:

$$
\left[\begin{array}{l}
\Delta \delta \\
\Delta V
\end{array}\right]=\left[S_{T}\right]\left[\begin{array}{l}
\Delta P \\
\Delta Q
\end{array}\right]
$$

In the above equation, $\Delta P_{k}=0$, where $k=1 \ldots h, k \neq i$, $j$ and $\Delta Q=0$. In the transaction matrix for seller area, in the place of generators, the PF value assigned is as follows:

$$
\Delta P_{S i}=+P F_{i} \text { subject to } \sum_{i=1}^{n} P F_{i}=1
$$

Meanwhile, in the transaction matrix for the buyer area, in the place of generators, the PF value assigned is the following:

$$
\Delta P_{B j}=-P F_{j} \text { subject to } \sum_{j=1}^{n} P F_{j}=1
$$

Where $n=$ the number of generators in the buyer and seller areas. All other entries in the buyer and seller area transaction matrices other than $\Delta P_{S i}$ and $\Delta P_{B j}$ are zeros. The change in voltage angle and magnitude at all buses present in the areas are calculated and hence the new voltage profile can be determined. Area wise PTDF is simply a function of these voltages and angle sensitivities, therefore, the calculation of multi-area ATC is similar to the 
procedure followed for single area ATC. More information about multi-area ATC is available in a previous study [6].

\section{FACTS Devices}

The insertion of FACTS devices in electrical systems seems to be a promising strategy to increase available transfer capability (ATC) [7]-[10].

\subsection{Selection of Devices}

FACTS devices are categorized under four different headings as series controllers, shunt controllers, combined seriesshunt controllers and combined series-series controllers. In this paper, one device from each category is selected i.e., TCSC from series controllers, SVC from shunt controllers and UPFC from combined series-shunt controllers.

TCSC is connected in series with the line conductors to compensate for the inductive reactance of the line. It may have one of the two possible characteristics namely capacitive or inductive, respectively to decrease or increase the reactance of the line $X_{L}$ respectively. Moreover, in order not to overcompensate the line, the maximum value of the capacitance is fixed at $-0.8 X_{L}$ while that for inductance, it is $0.2 X_{L}$. Although TCSC is not usually installed for voltage control purpose, it does contribute for better voltage profile and reactive power control.

SVC is used for voltage control applications. It helps to maintain a bus voltage at a desired value during load variations. The SVC may have two characteristics namely, inductive or capacitive. In the inductive mode, it absorbs reactive power, whereas in the capacitive mode, reactive power is injected. It may take values characterized by the reactive power injected or absorbed at the voltage of 1 p.u. The values are between -100 Mvar and 100 Mvar.

The UPFC is capable of providing active and reactive power control, as well as adaptive voltage magnitude control and regulates all the three variables simultaneously or any combination of them, provided no operating limits are violated. The UPFC may act as an SVC, a TCSC or a phase shift controller. The versatility afforded by the UPFC makes it a prime contender to provide many of the control functions required to solve a wide range of dynamic and steady state problems encountered in electrical power networks [9]. UPFC can be modeled as a combination of one series element i.e., TCSC and a shunt element i.e., SVC [23]. Hence the operational range limits of TCSC and SVC can be applied to UPFC as well.

\subsection{Modeling of FACTS Devices}

TCSC has been modeled as a variable reactance inserted in the transmission line connected between buses. SVC is modeled as a reactive power source added or connected at the bus. Based on previous research [23], UPFC is modeled as combination of an SVC at a bus and a TCSC in the line connected to the same bus.

\subsection{Device Placement Strategy}

ATC value is greatly influenced by the power flow in the limiting line of the system. Therefore, a FACTS device is placed in the limiting line or at the corresponding bus to which the limiting line is connected depending on the type of device. Only one FACTS device per line is allowed. If only one device is used, it is placed in the first limiting line of the system. If three devices are to be inserted, then the first three limiting lines are selected. For this purpose, the limiting lines in the considered test systems are ranked and ordered based upon the power carrying capacity in the line. For the multi-type device category, TCSC is considered as the first device, SVC as the second and UPFC as the third.

If the device is TCSC, it is connected in series with the limiting line. If the device is SVC, then the type of originating bus and terminating bus of the limiting line is checked. If the one end bus is PV bus, it is discarded and if the other end bus is PQ bus, then SVC is connected. Suppose if two end buses happen to be PV buses, then the next limiting line in the order is selected and checked for type of bus. For UPFC, the series device TCSC is connected in series with the limiting line and the shunt device SVC is connected at PQ bus after checking the type of the end buses where the limiting line is connected.

\section{Problem Formulation}

The aim of the optimization is to perform the best utilization of the existing transmission lines. The objective is to maximize the ATC i.e., uncommitted active transfer capacity of the prescribed interface, when a transaction is taking place between a seller bus (m) and buyer bus(n). It is represented as follows:

$$
\operatorname{Maximize}\left(A T C_{m n}\right)
$$

Where

$$
A T C_{m n}=\min \left\{T_{i j, m n}\right\}, i j \in N_{L} \text { as given in equation (2) }
$$

\subsection{FACTS device's constraints}

The constraints on the FACTS devices used in this work are given below:

$$
\begin{aligned}
& \text { i) }-0.8 X_{L} \leq X_{T C S C} \leq 0.2 X_{L} \quad p . u \\
& \text { ii) }-100 \mathrm{MVAR} \leq Q_{S V C} \leq 100 \mathrm{MVAR} \\
& \text { iii) Equations(20)\&(21) for UPFC }
\end{aligned}
$$

Where $X_{T C S C}$ is the reactance added to the line by placing TCSC, $X_{\mathrm{L}}$ is the reactance of the line where TCSC is located and $\mathrm{Q}_{\mathrm{SVC}}$ is the reactive power injected at the bus by placing SVC. 


\subsection{Power Flow Constraints}

The power flow constraint is given by:

$$
g(|v|, \theta)=0
$$

Where

$$
\begin{aligned}
& g(V, \theta)=\left\{\begin{array}{c}
P_{i}(|v|, \theta)-P_{i}^{n e t} \\
Q_{i}(|v|, \theta)-Q_{i}^{\text {net }}
\end{array}\right\} \text { For each PQ bus } i \\
& \text { not including ref. bus }
\end{aligned}
$$

$P_{i}, Q_{i}$ represents calculated real and reactive power for PQ bus i respectively. $P_{i}^{\text {net }}$ and $Q_{i}^{\text {net }}$ denotes specified real and reactive power PQ bus i respectively. $P_{m}$ and $P_{m}^{\text {net }}$ represents calculated and specified real power for PV bus $\mathrm{m}$, respectively. $|v|$ and $\theta$ represents voltage magnitude and phase angles at different buses, respectively.

\subsection{Installation Cost}

The installation cost of the corresponding FACTS devices are given by,

$$
I C=C^{*} S^{*} 1000
$$

where $I C$ denotes optimal installation cost of FACTS devices in US\$. $C$ represents cost of installation of FACTS devices in US \$/KVar.

The cost of installation of UPFC, TCSC and SVC are taken from Siemens data base and reported in [22]. The cost of installation of various FACTS devices are given by the following equations:

$$
\begin{aligned}
& C_{U P F C}=0.0003 S^{2}-0.2691 S+188.22 \\
& C_{T C S C}=0.0015 S^{2}-0.7130 S+153.75 \\
& C_{S V C}=0.0003 S^{2}-0.3051 S+127.38
\end{aligned}
$$

Where $S$ is the operating range of the FACTS devices in MVAR and it is given by:

$$
S=\left|Q_{2}-Q_{1}\right|
$$

Where $Q_{2}$ is the reactive power flow in the line after installing FACTS device in Mvar and $Q_{1}$ represents reactive power flow in the line before installing FACTS device in Mvar.

\section{Overview of PSO}

PSO is a population-based optimization method that was first proposed by Kennedy and Eberhart [19]. This technique finds the optimal solution using a population of particles. PSO is developed through the simulation of bird flocking in two-dimensional space. The position of each agent is represented in the $X-Y$ plane with position $\left(S_{x}, S_{y}\right)$, $V_{x}$ (velocity along $X$-axis), and $V_{y}$ (velocity along $Y$-axis). Modification of the agent position is realized by the position and velocity information. Bird flocking optimizes a certain objective function. Each agent knows its best value, thus called " $P_{\text {best }}$ ", which contains the information on position and velocities. This information is the analogy of personal experience of each agent. Moreover, each agent knows the best value so far in the group, " $G_{\text {best }}$ " among all " $P_{\text {best }}$ ". This information is the analogy of knowledge, on how the other neighboring agents have performed. Each agent tries to modify its position by considering current positions $\left(S_{x}, S_{y}\right)$, current velocities $\left(V_{x}, V_{y}\right)$, the individual intelligence $\left(P_{\text {best }}\right)$, and the group intelligence $\left(G_{\text {best }}\right)$.

The following equations are utilized, in computing the position and velocities, in the $X-Y$ plane:

$$
\begin{gathered}
V_{i}^{k+1}=W \times V_{i}^{k}+\left[C_{1} \times \operatorname{rand}_{1} \times\left(P_{\text {best }_{i}}-S_{i}^{k}\right)\right] \\
+\left[C_{2} \times \operatorname{rand}_{2} \times\left(G_{\text {best }}-S_{i}^{k}\right)\right] \\
S_{i}^{k+1}=S_{i}^{k}+V_{i}^{k+1}
\end{gathered}
$$

Where, $\mathrm{V}_{\mathrm{i}}^{\mathrm{k}+1}$ is the velocity of $\mathrm{i}^{\text {th }}$ individual at $(\mathrm{k}+1)^{\text {th }}$ iteration, $\mathrm{V}_{\mathrm{i}}^{\mathrm{k}}$ is the velocity of $\mathrm{i}^{\text {th }}$ individual at $\mathrm{k}^{\text {th }}$ iteration, $\mathrm{W}$ is the inertia weight, $\mathrm{C}_{1}$ and $\mathrm{C}_{2}$ are the positive constants having values $(0,2.5)$, rand $_{1}$ and rand $_{2}$ are the random numbers selected between 0 and $1, P_{\text {best }_{i}}$ is the best position of the $i^{\text {th }}$ individual, $G_{\text {best }}$ is the best position among the individuals (group best) and $\mathrm{S}_{\mathrm{i}}^{\mathrm{k}}$ is the position of $\mathrm{i}^{\mathrm{th}}$ individual at $\mathrm{k}^{\text {th }}$ iteration. The acceleration coefficients $\mathrm{C}_{1}$, and $\mathrm{C}_{2}$ control how far a particle will move in a single iteration. Typically, these are both set to a value of 2.5.

The velocity of each particle is modified according to (22) and the minimum and maximum velocity of each variable in each particle is set within the limits of $V_{\min }$ and $V_{\max }$ respectively. The position is modified according to (23). The inertia weight factor " $W$ " is modified using (24) to enable quick convergence [20].

$$
W=W_{\max }-\frac{\left(W_{\max }-W_{\min }\right)}{\text { iter }_{\max }} \times \text { iter }
$$

Where $W_{\max }$ is the initial value of inertia weight equal to $0.9, W_{\min }$ is the final value of inertia weight equal to 0.4 , iter is the current iteration number and iter $_{\max }$ is the maximum iteration number. Small values of $w$ result in more rapid convergence usually on a suboptimal position, while a too large value may prevent divergence of solution. The 
PSO system combines two models; a social-only model and a cognition-only model. These models are represented by the velocity update, shown in (22). More information is also available in [20].

\section{Simulation Results and Discussions}

In this paper, for the single and multi-area ATC determination, the generator settings of the test systems are obtained from CEED environment as explained in [6, 18]. The thermal limit of each line is considered as a constraint. Three types of FACTS device i.e., TCSC, SVC and UPFC are employed separately first and in three similar and different device combinations to enhance ATC. One set of bilateral and multi-lateral transaction is considered for the two IEEE test systems in the single area configuration and one area-wise transaction is considered for the two IEEE test systems in the multi-area configuration. The optimal settings of FACTS devices are obtained from PSO Algorithm. Installation cost of FACTS devices has also been calculated and the best single and multi-type device is suggested for each transaction with reference to ATC value and cost of installation. The simulation studies are carried out on Intel Pentium Dual Core, $2.40 \mathrm{GHz}$ system in MATLAB 7.3 environment.

\subsection{Single area ATC Enhancement}

The bus data and line data of the two IEEE test systems are taken from [24] and the CEED base case values of the generators are obtained as explained in $[6,18]$.

\subsubsection{IEEE 30 Bus System}

One bilateral transaction between buses (2-28) and a multilateral transaction between buses $(2,11)-(28,26)$ are considered in this test system.

\section{Bilateral Transaction}

ATC value at the base case without employing FACTS device is determined first, afterwards ATC is determined by employing FACTS devices in the single and multi-type three similar and different device combinations. Table 1 shows the results. The first four limiting lines are obtained for this transaction and the order of limiting lines are lines 6-28, 2-6, 6-8 and 22-24. The PSO convergence curve for this transaction utilizing single UPFC is shown in Fig. 1.

In the multi-type, similar devices combination, three TCSCs are placed in the first three limiting lines i.e., 6-28, 2-6 and 6-8. Similarly, three SVCs are placed at buses 28,6 and 8 . For the three UPFCs, the placement of three TCSCs and three SVCs are similar to the three similar devices. In the single device type, UPFC is providing maximum enhancement of ATC. Considering multi-type similar and different device combinations, three UPFCs are providing maximum enhancement of ATC. However, considering the cost of installation, TCSC-SVC-UPFC combination seems to be very effective for this transaction.

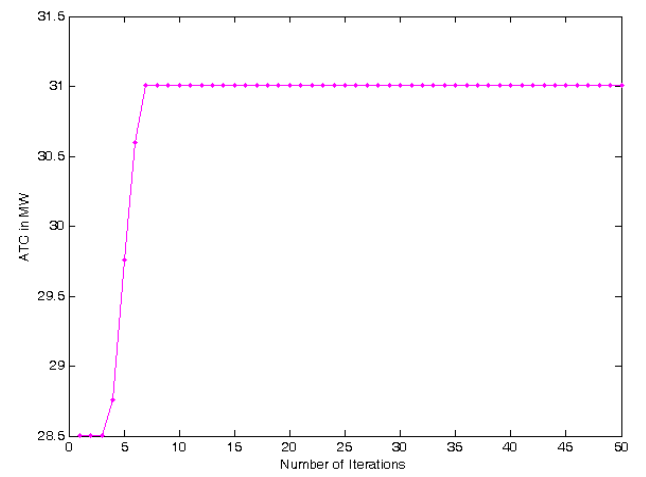

Fig. 1. PSO convergence curve for single UPFC.

Table 1. ATC enhancement results for bilateral transaction (2-28)

\begin{tabular}{|c|c|c|c|c|c|c|c|}
\hline \multirow{3}{*}{$\begin{array}{c}\text { ATC without } \\
\text { FACTS } \\
\text { (MW) }\end{array}$} & \multirow{3}{*}{$\begin{array}{c}\text { Type of FACTS } \\
\text { device(s) }\end{array}$} & \multirow{3}{*}{$\begin{array}{l}\text { ATC with } \\
\text { FACTS } \\
\text { (MW) }\end{array}$} & \multicolumn{4}{|c|}{ Settings and placement } & \multirow{3}{*}{$\begin{array}{c}\text { Installation Cost } \\
\left(\times 10^{6} \text { US } \$\right)\end{array}$} \\
\hline & & & \multirow{2}{*}{$\begin{array}{l}\text { TCSC } \\
\text { (p.u) }\end{array}$} & \multirow{2}{*}{$\begin{array}{c}\text { SVC } \\
\text { (Mvar) }\end{array}$} & \multicolumn{2}{|c|}{ UPFC } & \\
\hline & & & & & $\begin{array}{l}\text { TCSC } \\
\text { (p.u) }\end{array}$ & $\begin{array}{c}\text { SVC } \\
\text { (Mvar) }\end{array}$ & \\
\hline \multirow{7}{*}{24.821} & TCSC & 27.614 & $\begin{array}{r}0.030 \\
(6-28) \\
\end{array}$ & - & - & - & 0.29 \\
\hline & SVC & 25.413 & - & $\begin{array}{l}-92.772 \\
\text { (Bus 28) }\end{array}$ & - & - & 4.66 \\
\hline & UPFC & 31.004 & - & - & $\begin{array}{r}0.030 \\
(6-28) \\
\end{array}$ & $\begin{array}{l}-49.313 \\
\text { (Bus 28) }\end{array}$ & 3.82 \\
\hline & $\begin{array}{l}\text { TCSC } \\
\text { TCSC } \\
\text { TCSC } \\
\end{array}$ & 24.756 & $\begin{array}{r}0.030 \\
-0.074 \\
-0.021 \\
\end{array}$ & - & - & - & 1.67 \\
\hline & $\begin{array}{l}\text { SVC } \\
\text { SVC } \\
\text { SVC }\end{array}$ & 25.637 & - & $\begin{array}{c}-100 \\
59.258 \\
-96.432\end{array}$ & - & - & 9.00 \\
\hline & $\begin{array}{l}\text { UPFC } \\
\text { UPFC } \\
\text { UPFC }\end{array}$ & 33.516 & - & - & $\begin{array}{r}0.026 \\
0.088 \\
-0.021 \\
\end{array}$ & $\begin{array}{l}-99.544 \\
-99.127 \\
-50.472 \\
\end{array}$ & 12.27 \\
\hline & $\begin{array}{c}\text { TCSC } \\
\text { SVC } \\
\text { UPFC }\end{array}$ & 30.938 & $\begin{array}{l}0.029 \\
(6-28)\end{array}$ & $\begin{array}{l}95.651 \\
\text { (Bus 6) }\end{array}$ & $\begin{array}{c}-0.021 \\
(6-8)\end{array}$ & $\begin{array}{l}97.228 \\
\text { (Bus 8) }\end{array}$ & 3.21 \\
\hline
\end{tabular}




\section{Multilateral Transaction}

The order of the first four limiting lines based on the power flow capacity is 6-28, 25-27, 9-11 and 27-30. The base case ATC value is found to be $16.951 \mathrm{MW}$. In the single device type, TCSC is placed in series with line 6-28 and its settings is 0.104 p.u. SVC is connected at bus 28 and its settings is -55.022 Mvar. For UPFC, the series element is connected in the line 6-28, while the shunt element is connected at bus 28 . The settings of the shunt and series elements are 0.046 p.u and -53.637 Mvar respectively. For the three similar device combinations, three TCSCs are placed in series with the lines 6-28, 25-27 and 9-11 with settings of 0.104 p.u, 0.030 p.u and -0.083 p.u respectively. Similarly, three SVCs are connected at buses 28, 25 and 9 with settings of -60.013 Mvar, -11.584 Mvar and 100 Mvar. For the three UPFCs, the settings of the series elements are -0.104 p.u, 0.030 p.u and -0.104 p.u. The three shunt elements have the settings are -53.081 Mvar, -91.774 Mvar and 100 Mvar respectively. For the three different device combination, TCSC is connected in the line 6-28 with setting of 0.029 p.u, SVC is connected at bus 25 with setting of -97.643 Mvar and for UPFC, the series element in the line 9-11and shunt element at bus 9. The corresponding settings are -0.046 p.u and 89.225 Mvar. Fig. 2 shows the ATC enhancement results with single and multi-type three similar and different device combinations.

The installation cost details are shown in Fig. 3. For the multi-lateral transaction, in the single device category, TCSC is considered to be the best since it provides maximum improvement of ATC with minimum cost of installation. In multi-type similar and different device combinations, three UPFCs are providing maximum enhancement of ATC at very high installation cost. However, considering the cost of installation, three SVCs are suggested to be the best for this transaction.

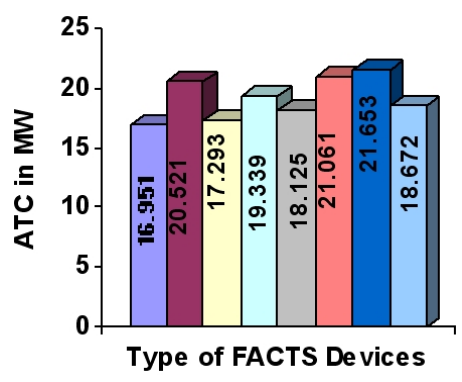

\begin{tabular}{|l|}
\hline$\square$ BASE CASE \\
$\square$ TCSC \\
$\square$ SVC \\
$\square$ UPFC \\
$\square$ TCSC-TCSC-TCSC \\
$\square$ SVC-SVC-SVC \\
$\square$ UPFC-UPFC-UPFC \\
$\square$ TCSC-SVC-UPFC \\
\hline
\end{tabular}

Fig. 2. ATC results - multilateral transaction of IEEE 30 bus system.
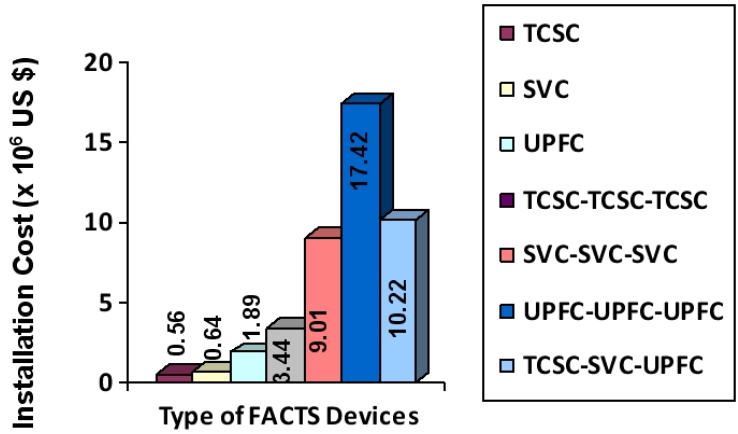

Fig. 3. Installation Cost - multilateral transaction of IEEE 30 bus system.

\subsubsection{IEEE 118 Bus System}

One bilateral transaction between buses (49-100) and a multilateral transaction between buses $(25,59,46)-(89,100$, $103,111)$ are considered in this large test system.

\section{Bilateral Transaction}

The first four limiting lines for this transaction is found to be lines $81-80,68-81,94-100$ and $69-77$. The results are given in Table 2 .

Table 2. ATC enhancement results for bilateral transaction (49-100)

\begin{tabular}{|c|c|c|c|c|c|c|c|}
\hline \multirow{3}{*}{$\begin{array}{l}\text { ATC without } \\
\text { FACTS } \\
\text { (MW) }\end{array}$} & \multirow{3}{*}{$\begin{array}{c}\text { Type of FACTS } \\
\text { device(s) }\end{array}$} & \multirow{3}{*}{$\begin{array}{l}\text { ATC with } \\
\text { FACTS } \\
\text { (MW) }\end{array}$} & \multicolumn{4}{|c|}{ Settings and placement } & \multirow{3}{*}{$\begin{array}{l}\text { Installation Cost } \\
\left(\times 10^{6} \text { US } \$\right)\end{array}$} \\
\hline & & & \multirow{2}{*}{$\begin{array}{l}\text { TCSC } \\
\text { (p.u) }\end{array}$} & \multirow{2}{*}{$\begin{array}{c}\text { SVC } \\
\text { (Mvar) }\end{array}$} & \multicolumn{2}{|c|}{ UPFC } & \\
\hline & & & & & $\begin{array}{l}\text { TCSC } \\
\text { (p.u) }\end{array}$ & $\begin{array}{c}\text { SVC } \\
\text { (Mvar) }\end{array}$ & \\
\hline \multirow{7}{*}{393.851} & TCSC & 425.984 & $0.019(81-80)$ & - & - & - & 5.63 \\
\hline & SVC & 395.940 & - & $\begin{array}{l}-97.025 \\
\text { (Bus 81) }\end{array}$ & - & - & 3.02 \\
\hline & UPFC & 425.986 & - & - & $0.018(81-80)$ & -68.213 (Bus 81) & 10.18 \\
\hline & $\begin{array}{l}\text { TCSC } \\
\text { TCSC } \\
\text { TCSC }\end{array}$ & 448.845 & $\begin{array}{l}0.018 \\
0.010 \\
0.007\end{array}$ & - & - & - & 11.90 \\
\hline & $\begin{array}{l}\text { SVC } \\
\text { SVC } \\
\text { SVC }\end{array}$ & 397.085 & - & $\begin{array}{c}-100 \\
-93.664 \\
98.335\end{array}$ & - & - & 7.69 \\
\hline & $\begin{array}{l}\text { UPFC } \\
\text { UPFC } \\
\text { UPFC }\end{array}$ & 447.789 & - & - & $\begin{array}{c}0.019 \\
0.010 \\
-0.018\end{array}$ & $\begin{array}{l}-90.644 \\
-81.233 \\
-85.301\end{array}$ & 9.67 \\
\hline & $\begin{array}{l}\text { TCSC } \\
\text { SVC } \\
\text { UPFC }\end{array}$ & 428.891 & $\begin{array}{c}0.018 \\
(81-80)\end{array}$ & $\begin{array}{l}-95.972 \\
\text { (Bus 81) }\end{array}$ & $\begin{array}{c}-0.027 \\
(94-100)\end{array}$ & $\begin{array}{c}91.766 \\
\text { (Bus 94) }\end{array}$ & 11.35 \\
\hline
\end{tabular}


In the multi-type, similar devices combination, three TCSCs are placed in the first three limiting lines i.e., 81-80, 68-81 and 94-100. Similarly, three SVCs are connected at buses 81,68 and 94 . For the three UPFCs, the placement of three TCSCs and three SVCs are the same as that of the three similar devices mentioned above.

In the single device category, UPFC and TCSC are providing equal improvement in ATC value. However, the installation cost for UPFC is almost twice times when compared with that for TCSC. Therefore, TCSC is the effective device for this transaction. Considering multi-type similar and different device combinations, three TCSCs are providing maximum enhancement compared to all other combinations. Therefore, for this transaction, the combination of three TCSCs combination is the most effective followed by the three UPFCs.

\section{Multilateral Transaction}

The four limiting lines in the order of power flow for this transaction are 100-103, 81-80, 69-77 and 68-81. The ATC value without FACTS device is $51.072 \mathrm{MW}$. The obtained ATC enhancement results are shown in Fig. 4. The installation cost details are shown in Fig. 5. In the single device type, TCSC is placed in series with the line 100-103 with settings of 0.026 p.u. Since buses 100 and 103 are PV buses, SVC is connected at bus 81 with settings of 65.773 Mvar. For UPFC, since buses 100 and 103 are PV buses, the series element is connected in the line 81-80 and the shunt element is connected at the bus 81 . The settings of the shunt and series elements are 0.026 p.u and -58.961 Mvar respectively. For the three similar device combinations, three TCSCs are placed in series with the lines 100-103, 81-80 and 69-77 with settings of 0.026 p.u, -0.008 p.u and -0.010 p.u. Similarly, three SVCs are connected at buses 81 , 77 and 68 with settings of 43.882 Mvar, 85.406 Mvar and 100 Mvar respectively. For the three UPFCs, the settings of the series elements are 0.0262 p.u, 0.003 p.u and -0.010 p.u respectively. The settings of the three shunt elements are 15.048 Mvar, -72.141 Mvar and 81.511Mvar. For the three different device combination, TCSC is connected in the line $100-103$ with setting of $0.027 \mathrm{p} . \mathrm{u}, \mathrm{SVC}$ is connected at bus 81 with setting of -66.458 Mvar and for UPFC, the series element in the line 69-77 and shunt element at bus 77 . The corresponding settings are -0.010 p.u and 90.973 Mvar.

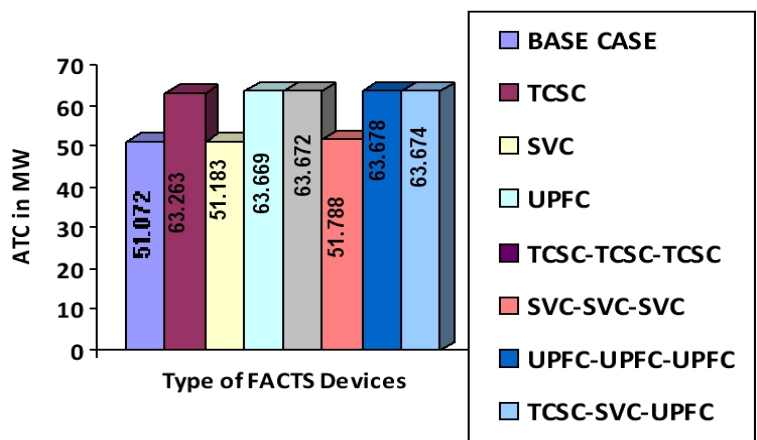

Fig. 4. ATC results- multilateral transaction of IEEE 118 bus system.

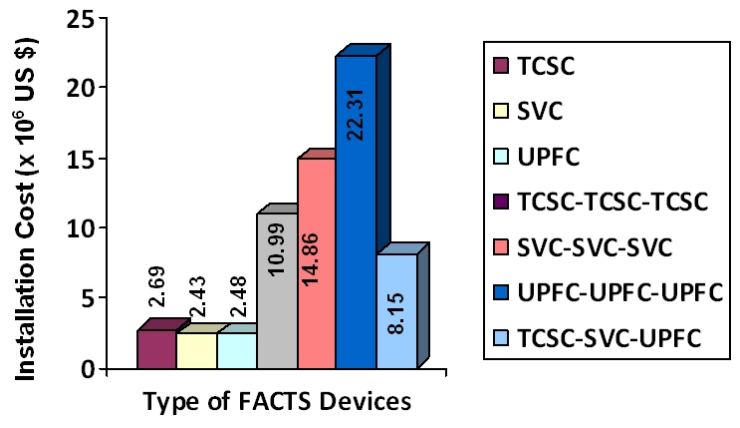

Fig. 5. Installation cost- multilateral transaction of IEEE 118 bus system.

For this multi-lateral transaction, UPFC is the best device in the single device type. SVC and three SVC combinations are proved to be ineffective for this multilateral transaction. In the multitype, similar and different device combinations, three UPFCs and TCSCSVC-UPFC combinations are producing equal enhancement. Cosidering the cost details, the TCSC-SVC-UPFC combination is proved to most promising one.

\subsection{Multi- area ATC Enhancement}

For the multi-area ATC determination, two areas are considered for the IEEE 30 bus system and three areas are considered for the IEEE 118 bus system.

\subsubsection{IEEE 30 Bus System}

There are six generators present in this system. Generators at buses 8,11 and 13 are considered in area 1, while the remaining generators at buses 1,2 and 5 are considered in area 2 . The tie-lines existing between the two areas are shown in Fig. 6. Transaction is carried out between Area 1 and Area 2. The first four limiting lines are lines 12-13, 1523, 6-8 and 15-18. Table 3 shows the ATC improvement results for this area- wise transaction.

In the multi-type, similar devices combination, three TCSCs are placed in the first three limiting lines i.e., 12-13, 15-23 and 6-8. Similarly, three SVCs are connected at buses 12,23 and 8 . For the three UPFCs, placement of three TCSCs and three SVCs is the same as that of the three similar devices.

In the single device type, TCSC is providing maximum enhancement of ATC with minimum cost. Considering multi-type similar and different device combinations, three UPFCs are providing the maximum enhancement of ATC but its cost is moderately high. In addition, the combination

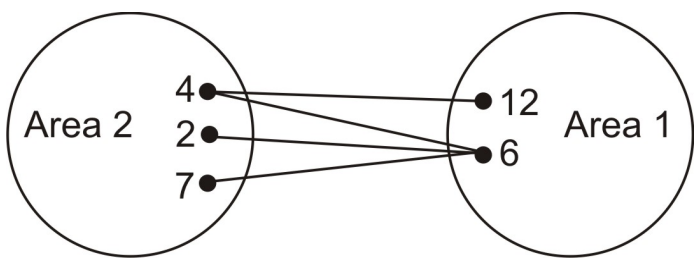

Fig. 6. Tie-lines between areas - IEEE 30 Bus system. 
Table 3. Multi-area ATC Enhancement results for IEEE 30 Bus system

\begin{tabular}{|c|c|c|c|c|c|c|c|}
\hline \multirow{3}{*}{$\begin{array}{c}\text { ATC without } \\
\text { FACTS } \\
(\mathrm{MW})\end{array}$} & \multirow{3}{*}{$\begin{array}{c}\text { Type of FACTS } \\
\text { device(s) }\end{array}$} & \multirow{3}{*}{$\begin{array}{c}\text { ATC with FACTS } \\
\text { (MW) }\end{array}$} & \multicolumn{4}{|c|}{ Settings and placement } & \multirow{3}{*}{$\begin{array}{c}\text { Installation cost } \\
\left(\times 10^{6} \text { US \$) }\right.\end{array}$} \\
\hline & & & \multirow{2}{*}{$\begin{array}{l}\text { TCSC } \\
\text { (p.u) }\end{array}$} & \multirow{2}{*}{$\begin{array}{c}\text { SVC } \\
\text { (Mvar) }\end{array}$} & \multicolumn{2}{|c|}{ UPFC } & \\
\hline & & & & & $\begin{array}{l}\text { TCSC } \\
\text { (p.u) }\end{array}$ & $\begin{array}{c}\text { SVC } \\
\text { (Mvar) }\end{array}$ & \\
\hline \multirow{7}{*}{92.613} & TCSC & 94.552 & $\begin{array}{c}0.067 \\
(12-13)\end{array}$ & - & - & - & 2.28 \\
\hline & SVC & 93.258 & - & $\begin{array}{c}-95.771 \\
\text { (Bus 12) }\end{array}$ & - & - & 2.69 \\
\hline & UPFC & 94.053 & - & - & $\begin{array}{c}0.070 \\
(12-13)\end{array}$ & $\begin{array}{l}-83.788 \\
\text { (Bus 12) }\end{array}$ & 3.06 \\
\hline & $\begin{array}{l}\text { TCSC } \\
\text { TCSC } \\
\text { TCSC }\end{array}$ & 95.710 & $\begin{array}{c}-0.0346 \\
-0.0128 \\
0.010\end{array}$ & - & - & - & 2.67 \\
\hline & $\begin{array}{l}\text { SVC } \\
\text { SVC } \\
\text { SVC }\end{array}$ & 95.299 & - & $\begin{array}{c}15.589 \\
-83.552 \\
11.077\end{array}$ & - & - & 5.53 \\
\hline & $\begin{array}{l}\text { UPFC } \\
\text { UPFC } \\
\text { UPFC }\end{array}$ & 98.038 & - & - & $\begin{array}{l}0.048 \\
0.017 \\
0.021 \\
\end{array}$ & $\begin{array}{c}-100 \\
3.446 \\
-85.638 \\
\end{array}$ & 6.12 \\
\hline & $\begin{array}{l}\text { TCSC } \\
\text { SVC } \\
\text { UPFC }\end{array}$ & 96.371 & $\begin{array}{l}-0.054 \\
(12-13)\end{array}$ & $\begin{array}{l}-57.017 \\
\text { (Bus 23) }\end{array}$ & $\begin{array}{l}0.021 \\
(6-8)\end{array}$ & $\begin{array}{l}-69.293 \\
\text { (Bus 6) }\end{array}$ & 3.55 \\
\hline
\end{tabular}

TCSC-SVC-UPFC seems to be the next best as it has provided marginal improvement of ATC at minimum cost of installation.

\subsubsection{IEEE 118 Bus system}

For the multi-area ATC evaluation, three areas are considered in the IEEE 118 bus system. This system has 19 generators. The generators and buses allocation for each area is given in Table 4. The lines between area 1 and area 2 are the lines between buses 15-33, 19-34, 30-38, 75-69, $75-118,75-77$ and 70-69. The lines connecting area 2 and area 3 are the lines between buses 77-82, 80-96, 97-96, 98100 and 99-100. Similarly, the lines connecting area 1 and area 3 are the lines between buses 70-24, 72-24 and 23-24. Transactions are carried out between area 1 and area 2; area 1 and area 3 ; and area 2 and area 3 .

The order of first four limiting lines is 81-80, 68-81, 6977 and 100-103. Transaction is carried out between area 2area 3 . The enhanced multi-area ATC results are shown in Fig. 7 and the installation cost details are shown in Fig. 8. In the single device type, TCSC is connected in series with the first limiting line $81-80$ and its setting is 0.018 p.u. SVC is connected at bus 81 and the Mvar settings obtained from the PSO is -99.231 Mvar. For UPFC, the series element in the line $81-80$ has the setting of 0.019 p.u and the shunt element at bus 81 has the setting of -67.144 Mvar.

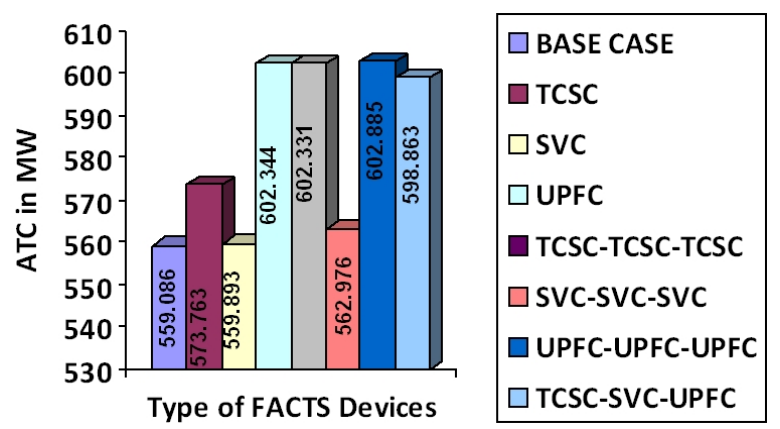

Fig. 7. Multi-area ATC enhancement results- IEEE 118 bus system.

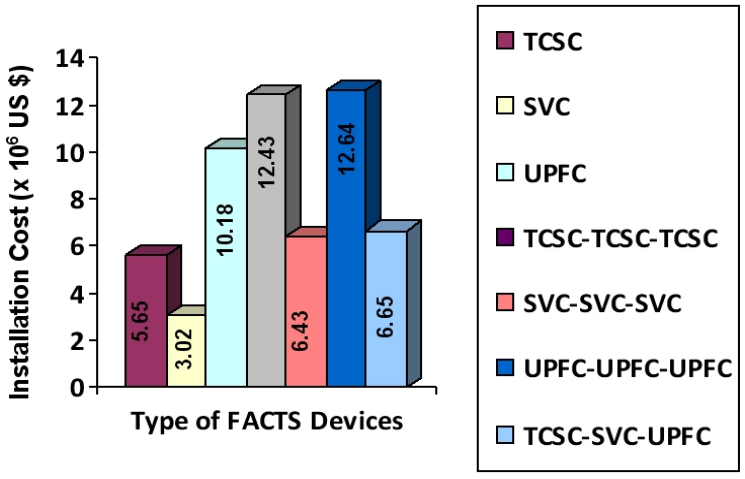

Fig. 8. Installation cost details -IEEE 118 bus system.

Table 4. Area-wise generators / buses allocation for IEEE 118 bus system

\begin{tabular}{c|c|c|c|c|c}
\hline \multicolumn{3}{|c|}{ Area / Generators } & \multicolumn{2}{c}{ Area / Buses } \\
\hline Area 1 & Area 2 & Area 3 & Area 1 & Area 2 \\
\hline \multirow{2}{*}{$10,12,25,26,31$} & $\begin{array}{c}46,49,54,59,61, \\
65,66,69,80\end{array}$ & $87,89,100,103,111$ & $\begin{array}{c}1-23,25-35, \\
70-75,113-115,117\end{array}$ & $\begin{array}{c}33-69,76-81,97-99, \\
116,118\end{array}$ \\
\hline
\end{tabular}


In the three similar device combinations, three TCSCs are placed in series with the lines 81-80, 68-81 and 69-77 with settings of -0.019 p.u, 0.010 p.u and 0.050 p.u. respectively. Similarly, three SVCs are connected at buses 81, 68 and 77 with settings of -47.897 Mvar, -100 Mvar and 95.846 Mvar respectively. For the three UPFCs, the settings of the series elements are 0.018 p.u, -0.0003 p.u and -0.0005 p.u. The settings of the three shunt elements settings are -82.951 Mvar, -50.133 Mvar and -12.484 Mvar. For the TCSC-SVC-UPFC combination, the TCSC is connected in series with the line $81-80$, the SVC is connected at bus 81 , the series device of UPFC in the line 69-77 and the shunt device of UPFC at bus 77 . The corresponding settings are 0.017 p.u, -90.763 Mvar, 0.002 p.u and -29.18 Mvar.

For this transaction, in the single device type, UPFC has been proven to be more effective since it enhances ATC to the maximum. Considering all multi-type combinations, three TCSCs and three UPFCs are equally effective since the corresponding ATC values and installation costs are similar. However, three UPFCs have a slight edge over TCSCs.

\section{Conclusion}

FACTS devices can boost the single area ATC and multiarea ATC substantially. The considerable difference between ATC values with and without FACTS devices for the considered transactions justifies that the FACTS technology can offer an effective and promising solution to enhance the usable power transfer capability, thereby improving transmission services of the competitive electricity market.

The effect of FACTS devices on ATC enhancement is system dependent. For the bilateral, multilateral and areawise transactions considered in the two IEEE test systems, the role played separately by TCSC, SVC and UPFC for boosting ATC in single device type and multi-type three similar and three different devices combinations are analyzed. Effective single device and effective combination of devices have also been suggested for the considered transactions.

\section{References}

[1] J.Weber, "Efficient Available Transfer Capability Analysis using Linear methods", PSERC internet seminar, UL, USA, Nov 7, 2000.

[2] A.Kumar and S.C. Srivatsava, "AC Power Distribution Factors for allocating Power transactions in a deregulated environment", IEEE Power Engineering Review, pp. 42-43, 2002.

[3] A. Kumar, S.C. Srivatsava and S.N.Singh, "ATC determination in a competitive electricity market using AC Distribution Factors", Electrical Power components and Systems, Vol. 32, No. 9, pp. 927-939, 2004.
[4] A.M. Leite da silva, J.G.C. Costa, L.A.F. Manso and G.J. Anders, "Evaluation of transfer capabilities of transmission systems in competitive environments", Electrical Power and Energy systems, Vol. 26, No. 4, pp. 257-263, 2004.

[5] M.M Othman, A. Mohamed and A. Hussain, "Fast Evaluation of Available Transfer Capability using Cubic-spline interpolation technique", Electric Power systems research, Vol. 73, No. 3, pp. 335-342, 2005.

[6] B.V. Manikandan, S. Charles Raja, P. Venkatesh and P.S Kannan, "Available Transfer Capability Determination in the Restructured Electricity Market. Electrical Power Components and Systems, Vol. 36, No. 9, pp. 941-959, 2008.

[7] Y. Xiao and Y.H. Song, "Application of Stochastic Programming for Available Transfer Capability Enhancement using FACTS Devices", Proceedings of 2000 IEEE/PES Summer Meeting, Seattle, WA, Vol. 1, pp. 508-515, 2000.

[8] Y. Xiao, Y.H.Song and Y.Z. Sun, "Application of Unified Power Flow Controller to Available Transfer Capability Enhancement" IEEE Power Engineering Review, Vol. 72, pp.66-68, 2001.

[9] K.S.Verma, S.N. Singh and H.O. Gupta, "FACTS device Location for Enhancement of Total Transfer Capability", IEEE Power Winter meeting, January, Ohio, USA, Vol. 2, pp. 522-527, 2001.

[10] Y. Xiao, Y.H. Song, C.C. Liu and Y.Z. Sun, "Available transfer capability enhancement using FACTS devices" IEEE Transactions on Power Systems, Vol. 18, No. 1, pp. 305-312, 2003.

[11] D.J. Gotham and G.T. Heydt, " Power Flow control and power flow studies for systems with FACTS devices" IEEE Transactions on Power Systems, Vol. 13, No. 1, pp. 60-65, 1998.

[12] D. Povh, "Modeling of FACTS in power system studies. IEEE Power Engineering Society Winter Meeting, Vol. 2, pp. 1435-1439, 2000.

[13] A. Kazemi and B. Badrzadeh, "Modeling and simulation of SVC and TCSC to study their limits on maximum loadability point", Electrical Power and Energy Systems, Vol. 26, pp. 619-626, 2004.

[14] S.N. Singh, "Role of FACTS devices in competitive power market. Proceeding of short term course on Electric Power system operation and management in restructured environment (IIT, Kanpur), pp. A.71A.80, 2003.

[15] H. Sawhney and B. Jeyasurya, B, "Application of Unified Power Flow Controller for Available Transfer capability enhancement", Electric Power Systems Research, Vol. 69, No. 2-3, pp. 155-160, 2004.

[16] S. Gerbex, R. Cherkaoui and A.J. Germond, "Optimal Location of Multi-type FACTS devices by Means of Genetic Algorithm", IEEE Transactions on Power Systems, Vol. 16, No. 3, pp. 537-544, 2001.

[17] T.T. Ma, "Enhancement of Power Transmission systems by using multiple UPFC on Evolutionary Programming", IEEE Bologna Power Technical Confer- 
ence, Vol. 4, pp. 23-26, 2003.

[18] P. Venkatesh, R. Gnanadass and N.P. Padhy, "Comparison and application of Evolutionary programming techniques to combined economic emission dispatch with line flow constraint", IEEE Transactions on Power systems, Vol. 18, No. 2, 688-697, 2003.

[19] J.Kennedy and R. Eberhart, "Particle Swarm Optimization", Proceedings of IEEE international conference on Neural Networks, Piscataway, NJ, Vol. IV, pp. 1942-1948, 1995.

[20] M.A.Abido, "Optimal Power Flow using Particle Swarm Optimisation", Electrical Power and Energy Systems, Vol. 24, 563-571, 2002.

[21] S.Kannan, S.M.R.Slochanal, P.Subbaraj and N.P.Padhy, "Application of Particle swarm optimization technique and its variants to generation expansion planning problem", Electric Power Systems Research, Vol. 70, pp. 203-210, 2004.

[22] L.J. Cai, I. Erlich and G. Stamtsis, "Optimal choice and allocation of FACTS devices in deregulated electricity market using genetic algorithms", IEEE PES Power system conference and Exposition, USA, pp. 10-13, 2004.

[23] M. Saravanan, S.M.R. Sulochanal, P.Venkatesh and J.P.S.Abraham, "Application of particle swarm optimization technique for optimal location of FACTS devices considering cost of installation and system loadability”, Electric Power Systems Research, Vol. 77, No. 3-4, pp. 276-283, 2005.

[24] http://www.ee.washington.edu/research/ pstca

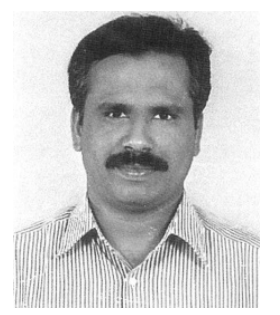

B.V. Manikandan obtained his B.E., in Electrical and Electronics Engineering and M.E., in Power Systems Engineering from Madurai Kamaraj University in 1990 and in 1992 respectively, and Ph.D., degree from Anna University, Chennai in 2010. His Ph.D., work deals with issues of power system restructuring. His special fields of interest includes power system restructuring issues and application of FACTS controllers to power system. He is presently working as Assistant Professor in the Department of Electrical and Electronics Engineering of Mepco Schlenk Engineering College, Sivakasi.

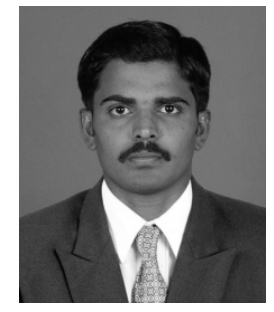

S. Charles Raja is presently working as Lecturer in the Department of Electrical and Electronics Engineering of Thiagarajar College of Engineering, Madurai. He obtained his B.E., in Electrical and Electronics Engineering in 2005 and M.E., in Power Systems Engineering in 2007 from Anna University, Chennai. His topics of interest include Power system security, Power system optimization techniques, control systems, application of FACTS controllers for all power system problems and power system deregulation.

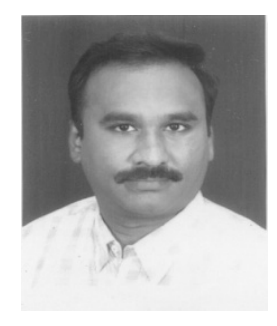

P. Venkatesh received his degree in Electrical and Electronics Engineering, Masters in Power System Engineering with distinction and Ph.D from Madurai Kamaraj University, India in 1991, 1994 and 2003, respectively, His area of interest is the application of evolutionary computation techniques to power system problems and power system restructuring. He has received the Boyscast Fellowship award in 2006 from the Department of Science and Technology, India for carrying out research work at Pennsylvania State University, USA. He has more than 16 papers published in reputable journals to his credit. He has chaired many technical sessions in seminars/workshops and gave number of invited lectures in many forums. He is currently, an Associate Professor in the Department of Electrical and Electronics Engineering, Thiagarajar College of Engineering, Madurai, India. 